RAFHAEL ROMERO BENTOS

\title{
A NÃO CUMULATIVIDADE DO ICMS PARA OS PRESTADORES DE SERVIÇOS (TRANSPORTE E COMUNICAÇÃO)
}

\author{
Mestrado em Direito
}

Professor Titular Doutor Paulo de Barros Carvalho

UNIVERSIDADE DE SÃO PAULO

FACULDADE DE DIREITO

São Paulo-SP 

RAFHAEL ROMERO BENTOS

\section{A NÃO CUMULATIVIDADE DO ICMS PARA OS PRESTADORES DE SERVIÇOS (TRANSPORTE E COMUNICAÇÃO)}

Dissertação apresentada à Banca Examinadora do Programa de Pós-Graduação em Direito, da Faculdade de Direito da Universidade de São Paulo, como exigência parcial para obtenção do título de Mestre em Direito, na área de concentração Direito Econômico, Financeiro e Tributário, sob orientação do Professor Titular Doutor Paulo de Barros Carvalho.

UNIVERSIDADE DE SÃO PAULO

FACULDADE DE DIREITO

São Paulo-SP 



\section{Banca Examinadora:}

Orientador: Professor Titular Paulo de Barros Carvalho Instituição: Faculdade de Direito da USP Assinatura:

Professor: Instituição: Assinatura:

Professor: Instituição: Assinatura: 

Àqueles que acreditam em mim, mais do que eu mesmo: Maria Neli Romero Bentos, Antônio Kleber Bentos, Emanuel Vinícius Romero Bentos, Ariel Romero Bentos, Vinícius Berná Marques Pinto, Daniela Martins Romero, Isabella Alves Romero e Márcia Maria Bentos.

À Maria Cláudia Romero e Márcia Regina Berná, in memoriam, que nos deixaram tão cedo. Aprenderemos a viver com saudade e com a certeza de que as pessoas não morrem, ficam encantadas (Guimarães Rosa). 



\section{AGRADECIMENTOS}

Após 3 anos de dedicação, devo agradecer a todos aqueles que contribuíram para cada linha dessa dissertação, seja trazendo ideias e agregando conhecimento, seja motivando-me diariamente para que pudesse concluir esse estudo.

Aos meus pais (Kleber e Neli), meus irmãos (Emanuel e Ariel) e minhas cunhadas (Isabella e Daniela), por traduzirem o significado de amor e segurança familiar.

Ao Vinícius, pela motivação constante, pelo companheirismo e paciência. São as horas roubadas de nossa convivência que contribuíram para o resultado desse estudo e que espero poder retribuir.

Ao Professor Paulo de Barros Carvalho, pela oportunidade ímpar na minha vida pessoal e acadêmica de cursar o mestrado sob sua orientação. São seus ensinamentos que influenciam e moldam minha trajetória profissional desde 2014. Muito obrigado!

Ao Professor André Mendes Moreira, pela paciência, disponibilidade em responder atenciosamente a cada e-mail (que não foram poucos) e sugestões ao longo de todo esse projeto.

Ao Professor Roberto Quiroga Mosquera, pelos exemplos diários de profissionalismo, caráter e liderança que tanto me inspiram. Cada conversa soa como uma lição!

Ao Professor Paulo Ayres Barreto, pela simpática convivência nas salas de aula da USP, pelo aprendizado semanal e pelas sugestões sempre precisas.

Aos amigos que viveram e compartilharam essa experiência tão de perto: Aline de Carvalho (sempre comigo), Diógenes Mendes, Paula de Freitas, Ana Fazzio, Cristiane Pires, José Luiz Crivelli, Maria Ângela Paulino, Lucas Galvão de Britto, Jacqueline Meyer, Thiago Wanderley e tantos outros da PUC-SP, Mundie Advogados e Mattos Filho, Veiga Filho, Marrey Jr. e Quiroga Advogados. 



\section{RESUMO}

ROMERO BENTOS, Rafhael. A Não Cumulatividade do ICMS para os Prestadores de Serviços (Transporte e Comunicação). Dissertação (Mestrado em Direito) - Faculdade de Direito, Universidade de São Paulo, São Paulo, 2017.

Este trabalho objetiva analisar a aplicação da não cumulatividade do ICMS para os prestadores de serviços (transporte e comunicação). Parte-se, assim, da análise histórica, constitucional e jurisprudencial desse princípio, a fim de se identificar e delimitar os critérios que autorizam o aproveitamento de créditos de ICMS para as pessoas jurídicas que atuam naqueles setores.

Palavras-chave: Princípio da Não Cumulatividade. Regra-Mariz de Incidência Tributária. ICMS. Prestações de Serviços. Transporte. Comunicação. 


\begin{abstract}
ROMERO BENTOS, Rafhael. The Non-Cumulativity of State-VAT (ICMS) for the Service Providers (Transportation and Communication), Degree (Master in Law) Faculty of Law, University of São Paulo, São Paulo, 2017.

This study aims to analyze the application of the Non-Cumulativity of State-VAT (ICMS) for the service providers (transportation and communication). Therefore, the examination of this principle is based on the historical, constitutional and the cases law, in order to identify and determine the criteria that authorize the use of ICMS credits for legal entities operating in those sectors.
\end{abstract}

Keywords: Principle of Non-Cumulativity. ICMS. Legal Standards of Tax Incidence. Service Providers. Transportation. Communication. 


\section{SUMÁRIO}

INTRODUÇÃO .13

\section{PARTE I}

1 SISTEMA JURÍDICO CONSTITUCIONAL ..................................................15

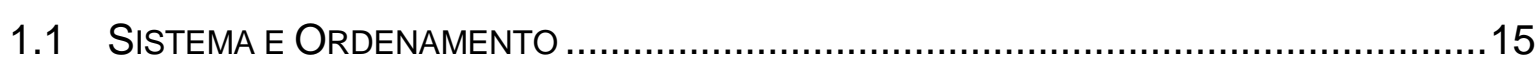

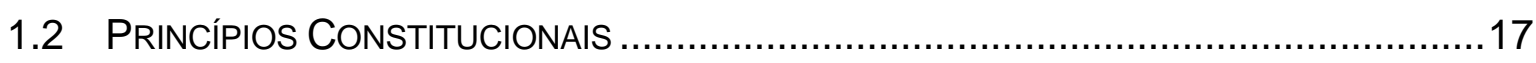

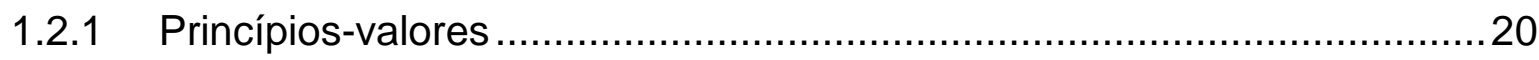

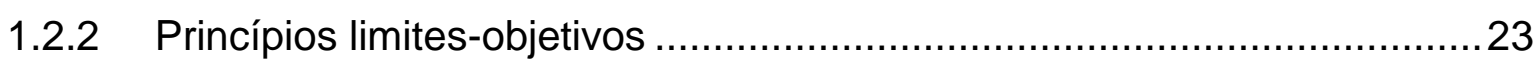

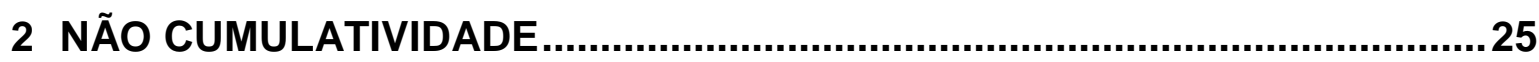

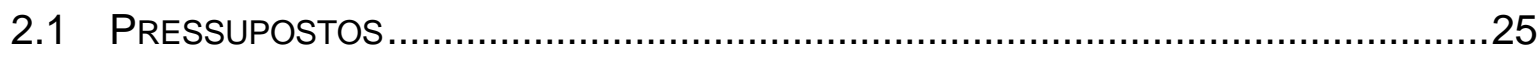

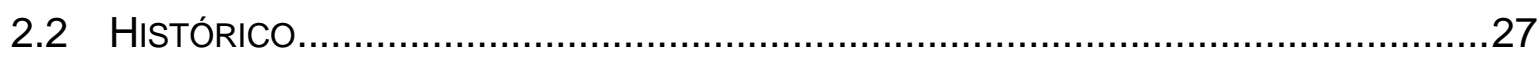

2.2.1 Surgimento da Não Cumulatividade no Brasil ......................................... 30

2.3 NÃo CUMULATIVIDAdE do ICMS NA CONSTITUIÇÃo FEDERAL E AXIOLOGIA ............31

2.3.1 Princípios-Valores relacionados a Não Cumulatividade ............................33

2.3.2 Exceções Constitucionais da Não Cumulatividade do ICMS: art. 155,

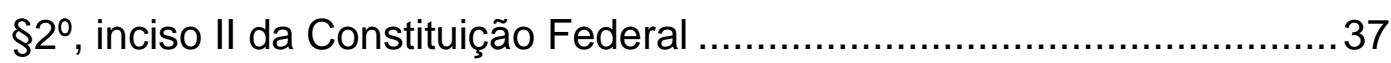

2.4 NÃO CUMULATIVIDADE dO IMPOStO SOBRE PROdUtOS INDUSTRIALIZADOS (IPI) ....42

2.5 NÃO CUMULATIVIDADE DAS CONTRIBUIÇÕES AO PIS E COFINS ...........................45

2.6 NÃo CumUlatividadE E A REGRA-MatRIZ dE INCIDÊNCIA TRIBUTÁRIA ..................49

2.7 TÉCNICAS dA NÃo CUMULATIVIDADE: MÉTOdOS DA AdIÇÃo E SUBTRAÇÃO.............51

2.8 TEORIAS DO CRÉDITO FísICO VERSUS CRÉDITO FINANCEIRO................................52

2.9 Crédito Físico versus Crédito FinanCeiro do ICMS NA LegISLAÇão

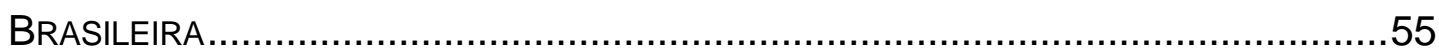

2.10 CRÉDITO FísICO VERSUS CRÉDITO FINANCEIRO DO ICMS NA JURISPRUDÊNCIA BRASILEIRA: SUPREMO TRIBUNAL FEDERAL

2.11 CRÉDITO FísICO VERSUS CRÉDITO FINANCEIRO DO ICMS NA JURISPRUDÊNCIA BRASILEIRA: SUPERIOR TRIBUNAL DE JUSTIÇA ...............................................70

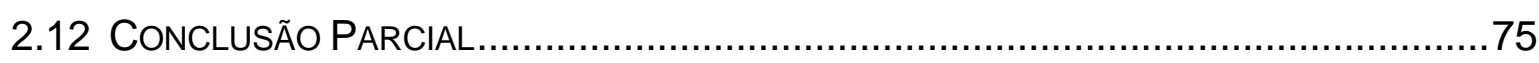




\section{PARTE II}

3 REGRA-MATRIZ DE INCIDÊNCIA TRIBUTÁRIA …................................... 79

3.1 ANTECEDENTE (HIPÓTESE DE INCIDÊNCIA TRIBUTÁRIA) …….............................

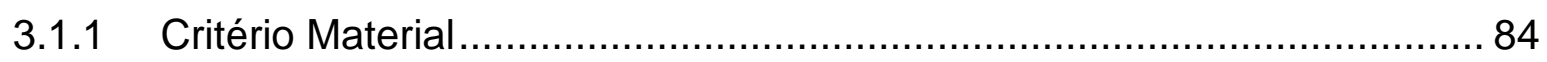

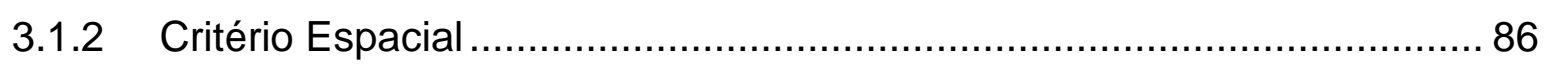

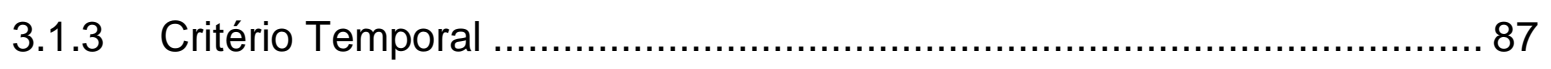

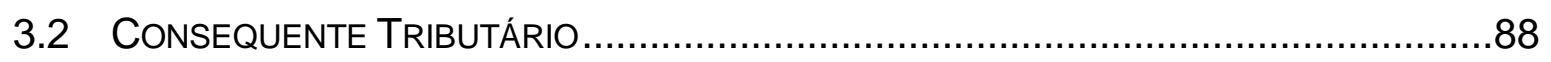

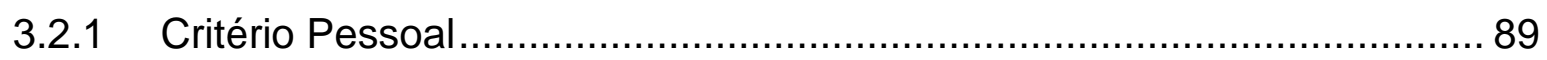

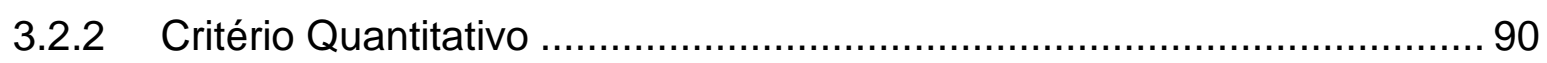

4 IMPOSTO SOBRE CIRCULAÇÃO DE MERCADORIAS E PRESTAÇÕES

DE SERVIÇOS DE TRANSPORTE INTERESTADUAL E INTERMUNICIPAL E DE COMUNICAÇÃO (ICMS) - NOÇÕES GERAIS........ 95

4.1 DEFINIÇÃO DE "PRESTAÇÃO DE SERVIÇOS" ....................................................98

4.2 ICMS SOBRE PRESTAÇõES DE SERVIÇOS DE TRANSPORTE - ConSIDERAÇÕES

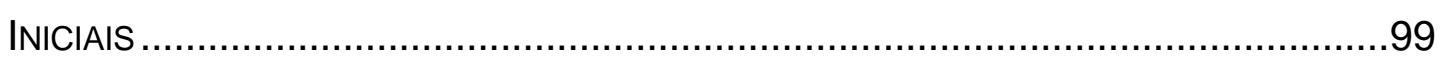

4.2.1 ICMS-Transporte - Critério Material .................................................... 100

4.2.1.1 Prestações de Serviços de Transporte: Subcontratação e

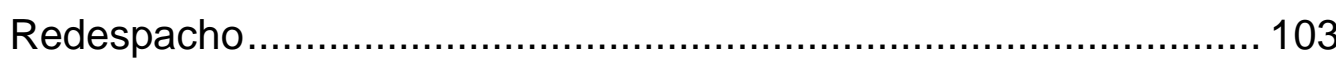

4.2.1.2 Controvérsias Jurisprudências Quanto ao Critério Material do

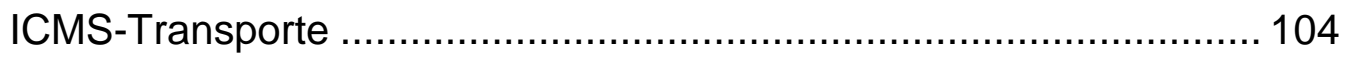

4.2.2 Critério Espacial do ICMS-Transporte ................................................... 106

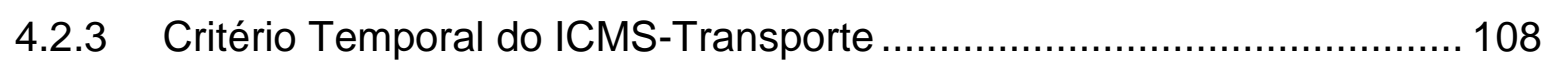

4.2.4 Critério Pessoal do ICMS-Transporte ..................................................... 109

4.2.5 Critério Quantitativo do ICMS-Transporte ......................................... 110

4.3 ICMS-COMUNICAÇÃO: CONSIDERAÇÕES INICIAIS............................................111

4.3.1 Critério Material do ICMS-Comunicação ............................................. 112

4.3.1.1 Serviços de Comunicação e Serviços de Telecomunicação ................ 116

4.3.1.2 Não incidência do ICMS sobre Serviços Conexos à Prestação dos Serviços de Comunicação (atividade-meio) ...................................... 117

4.3.1.3 Serviços de Provimento de Acesso à Internet ................................ 122

4.3.2 Critério Espacial do ICMS-Comunicação ............................................... 125

4.3.3 Critério Temporal do ICMS-Comunicação …….................................. 126 


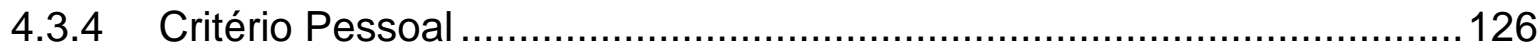

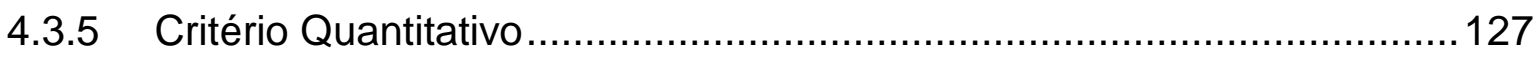

\section{PARTE III}

\section{NÃO CUMULATIVIDADE DO ICMS PARA OS PRESTADORES DE SERVIÇOS}

5.1 Conteúdo Mínimo da Não Cumulatividade do ICMS para Prestadores

DE SERVIÇOS: INSUMOS E O CRITÉRIO DA ESSENCIALIDADE

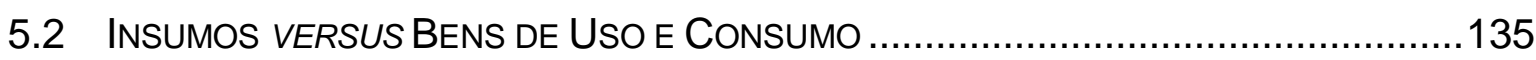

5.3 Ativo Permanente Versus Bens de Uso e Consumo ..................................137

5.4 NÃo Cumulatividade dos Prestadores de Serviços de Transporte...........138

5.4.1 Serviços de Transportes utilizados como Insumos de Outras Prestações de Serviços de Transporte.

5.4.2 Combustíveis Utilizados nas Prestações de Serviços de Transporte......141

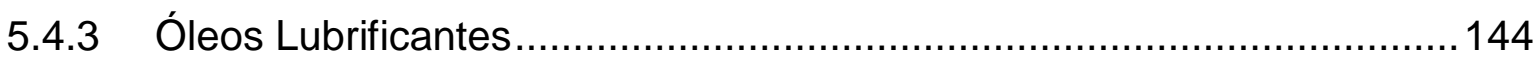

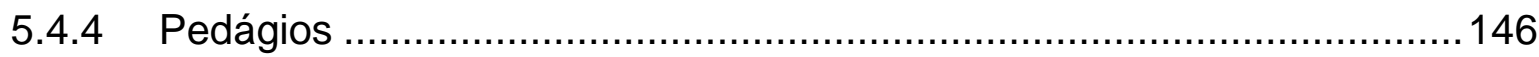

5.4.5 Sistema de Frenagem: Peças e Fluídos............................................ 147

5.4.6 Pneus de Veículos utilizados nas Prestações de Serviços .....................148

5.4.7 Energia Elétrica Consumida no Transporte Ferroviário .......................... 150

5.4.8 Areia Consumida no Transporte Ferroviário......................................... 151

5.5 NÃO CUMULATIVIDADE DOS PRESTADORES DE SERVIÇOS DE COMUNICAÇÃO ..........152

5.5.1 Aquisição de energia elétrica para prestação de serviços de comunicação

5.5.2 Créditos de ICMS relacionados à prestação de serviço de call center das empresas de comunicação

5.5.3 Créditos de ICMS na aquisição de bens destinados à manutenção e expansão de redes interna e externa de transmissão (como cabos, braçadeiras, fios, bastidores, etc.)

5.5.4 Contratos de comodato das prestadoras de serviços de comunicação e o pretendido estorno do crédito de ICMS .

5.5.5 Cessão de uso de redes e diferimento do ICMS em que o fisco interpreta como isenção (Convênio no 126/98, cláusula décima/Convênio ICMS no 16/2013)

5.5.6 Crédito de ICMS referente ao mobiliário dos pontos de revenda 
5.5.7 Aplicação comum: créditos de ICMS de optantes do Simples Nacional

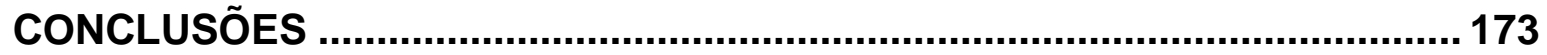

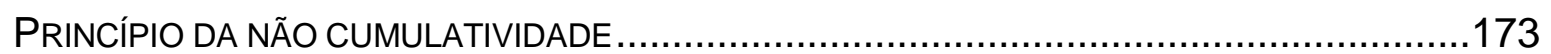

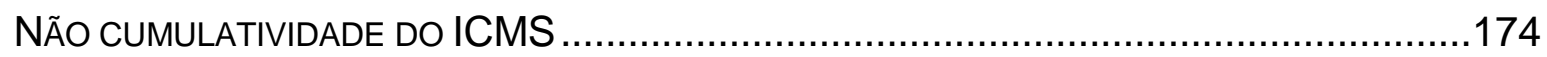

NÃo CuMULATIVIDADE do ICMS PARA OS PRESTAdoRES DE SERVIÇOS .......................175

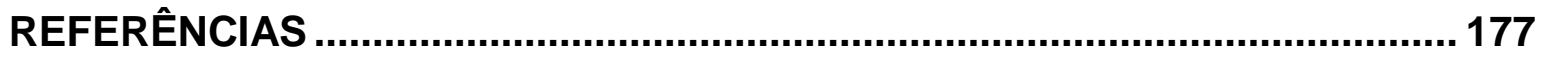




\section{INTRODUÇÃO}

Com o advento da atual Constituição Federal, o imposto que antes se limitava à materialidade sobre circulação de mercadorias (o antigo ICM) passou a abarcar também as prestações de serviços de transporte e comunicação (atual ICMS).

Ocorre que a herança do então ICM tem se propagado ao longo de todos esses anos e tem impedido a devida e minuciosa análise das novas materialidades do imposto, especialmente quanto ao direito ao aproveitamento de créditos estabelecido pelo princípio da não cumulatividade (art. 155, §2 inciso I da Constituição Federal).

Isso porque, na circulação de mercadorias, tem-se a saída de produtos físicos que são formados pelo emprego de insumos também físicos que são empregados diretamente e consumidos no processo produtivo. Por tal natureza, a legislação e jurisprudência têm autorizado o crédito do imposto referente às aquisições daqueles insumos que compõem diretamente o produto final.

De outro modo, nas prestações de serviços, as atividades-fim das pessoas jurídicas são bens incorpóreos e intangíveis, o que demanda especial análise quanto à natureza dessas atividades e impede a aplicação dos conceitos aplicáveis à circulação de mercadorias.

Considerando-se que não há produto físico, não se pode pretender aplicar às prestações de serviços aquelas acepções mais restritivas de direito ao aproveitamento de créditos de ICMS.

Exige-se, portanto, a análise detida da natureza dos serviços de transporte e comunicação frente aos postulados do princípio da não cumulatividade estabelecido pela Constituição Federal, a fim de identificar quais são as situações que devem autorizar o direito ao aproveitamento de créditos.

Diante desse contexto, o presente trabalho se propõe a analisar a não cumulatividade do ICMS para os prestadores de serviços de transporte e comunicação, privilegiando-se particularidades dessas atividades frente ao arcabouço constitucional.

Na Parte 1 (capítulos 1 e 2), têm-se as premissas do trabalho: analisa-se o sistema jurídico constitucional brasileiro, os princípios constitucionais e suas funções e, em razão da delimitação do presente estudo, o princípio da não 
cumulatividade do ICMS e suas particularidades, tais como: histórico, características elementares, teorias que direcionam tal princípio, análise da jurisprudência do Supremo Tribunal Federal e Superior Tribunal de Justiça quanto ao aproveitamento de créditos do ICMS.

Na Parte 2 (capítulos 3 e 4), tem-se o corpo do estudo, isso porque se analisa o conceito de regra-matriz de incidência tributária para, em seguida, construir-se a regra-matriz de incidência tributária do ICMS para os prestadores de serviços de transporte e comunicação.

Por tais capítulos, traçam-se as premissas, contexto e características dos prestadores de serviços de transporte e comunicação tributados pelo ICMS.

$\mathrm{Na}$ Parte 3 (capítulos 5 e 6), tem-se o estudo aprofundado da não cumulatividade do ICMS para tais prestadores de serviços, isso porque se analisa o teor do princípio constitucional frente às particularidades dessas atividades.

No capítulo 5, identifica-se o critério mínimo da não cumulatividade do ICMS e diversos exemplos pragmáticos e jurisprudenciais que devem autorizar o direito ao aproveitamento de créditos dos prestadores de serviços.

Por fim, o capítulo 6 trata das conclusões do presente estudo, que objetivam evidenciar as particularidades das atividades exercidas pelos prestadores de serviços, o que impede a aplicação dos antigos conceitos do ICM a essas novas materialidades e demanda o amplo direito ao aproveitamento de créditos, for força do princípio da não cumulatividade do ICMS previsto expressamente no Texto Constitucional. 


\section{CONCLUSÕES}

\section{Princípio da não cumulatividade}

O direito pode ser classificado como sistema, isso porque se trata de conjunto de elementos que se relacionam de inúmeras maneiras, a partir de um denominador comum, com objetivo de atuar dentro dos modais deônticos (proibido, permitido ou obrigatório).

Dentre as diversas normas do sistema jurídico, encontram-se os princípios constitucionais, que se dividem entre valores e limites-objetivos: os primeiros são conteúdos axiológicos que refletem os anseios e crenças da sociedade em determinado momento e servem de vetores para as atividades legislativa, executiva e jurídica; os segundos são instrumentos para a concreção daqueles conteúdos axiológicos.

Os princípios valores não permitem qualquer mitigação ou violação, isso porque aceitá-las é o mesmo que admitir que todos os anseios da sociedade sejam desprezados. Por sua vez, os limites-objetivos somente podem sofrer mitigações, desde que mecanismos de recomposição impeçam que os valores que Ihes são imanentes não sejam violados.

No sistema jurídico brasileiro, o art. 155, §2º, inciso I, da Constituição Federal positivou o princípio da não cumulatividade para o ICMS, que trata de mecanismo de apuração do quantum debeatur do imposto mediante a compensação dos valores devidos em cada operação/prestação de serviços com o montante cobrado nas etapas anteriores.

Em verdade, mais do que mecanismo de apuração do ICMS, a não cumulatividade do ICMS objetiva tutelar conteúdos axiológicos protegidos pelo sistema jurídico, como justiça fiscal, isonomia, capacidade contributiva, vedação ao confisco.

Trata-se, portanto, de princípio limite-objetivo, e não deve sofrer mitigações, caso haja violação àqueles valores. As únicas exceções (mitigações) previstas pelo Texto Constitucional se referem à vedação ao aproveitamento de créditos nas hipóteses de isenção e não incidência (art. 155, §2º, inciso II). 


\section{Não cumulatividade do ICMS}

A não cumulatividade adquiriu status constitucional com o advento da Emenda Constitucional no 18/1965, que extinguiu o Imposto de Consumo (IC) para dar lugar ao Imposto sobre Produtos Industrializados (IPI) e ao Imposto sobre o Consumo (ICM), que tinha como única materialidade a circulação de mercadorias.

Com o advento da Constituição Federal de 1988, incluíram-se novas materialidades ao antigo ICM, que passou a ser denominado ICMS, isso porque 0 art. 155, inciso II, da atual Carta Magna outorga competência aos Estados e Distrito Federal para instituir imposto sobre a prestação de serviços de transporte (interestadual e intermunicipal) e comunicação.

A despeito da extensão das materialidades do ICMS desde 1988, tem-se que a legislação e a jurisprudência atuais continuam presas aos critérios atinentes à circulação de mercadorias, o que se revela deveras prejudicial às materialidades de prestação de serviços e peculiaridades.

Isso porque o direito a crédito do ICM decorria das matérias-primas e bens intermediários que fossem, necessariamente, consumidos no processo produtivo e que integrassem fisicamente o produto final (teoria do crédito físico). Tal entendimento faz sentido ao passo que a única materialidade desse imposto era a circulação de mercadorias.

Ocorre, contudo, que o advento das novas materialidades de prestações de serviços estabeleceu ruptura àqueles antigos conceitos, pois se tratando de intangíveis, a teoria do crédito físico não encontra guarida.

Considerando-se que nas prestações de serviços não há produto final para integração física, nem mesmo saída física dos estabelecimentos, os critérios de autorização de créditos devem ser repensados.

Analisando-se a atual ordem constitucional, verifica-se que 0 art. 155, $\S 2^{\circ}$, inciso I, da Constituição Federal (não cumulatividade do ICMS) estabelece previsão ampla e irrestrita de direito à compensação. Tal dispositivo prevê o direito de abatimento, em cada etapa, dos montantes cobrados nas operações e prestações de serviços anteriores. A única vedação constitucional ao aproveitamento de crédito de ICMS ocorre nas hipóteses de isenção e não incidência (inciso II). 
Diante dessa a amplitude do direito ao aproveitamento de créditos, tem-se que a Carta Magna se baseia na teoria do crédito financeiro, o que autoriza a compensação de créditos de ICMS decorrentes da aquisição de mercadorias, matérias-primas e serviços que tenham sido tributados na etapa anterior e integrem, de qualquer forma, a atividade-fim das pessoas jurídicas.

Tanto o é, que a Lei Complementar ํㅡ 87/1996 estabelece os mecanismos de compensação do ICMS e prevê, expressamente, o direito ao aproveitamento de créditos decorrentes da aquisição de mercadorias destinadas ao uso e consumo ou ativo permanente, bem como o recebimento de serviços de transporte e comunicação (art. 20).

Conclui-se, pelo exposto, que o princípio da não cumulatividade do ICMS autoriza o amplo aproveitamento de créditos referentes aos montantes cobrados nas etapas anteriores (com pontual exceção) e, nos atuais termos da Constituição Federal, baseia-se na teoria do crédito financeiro.

\section{Não cumulatividade do ICMS para os Prestadores de Serviços}

Nos termos do art. 155, §2º, inciso I, da Constituição Federal, verifica-se que as pessoas jurídicas têm o direito ao aproveitamento de créditos de ICMS em razão de todas as aquisições de bens e serviços que sejam relacionados às suas atividades-fim, por força do princípio da não cumulatividade.

No caso dos prestadores de serviços tributados pelo ICMS, as atividadesfim são bens intangíveis, em que não se tem produto final físico. Exige-se, assim, especial atenção dos operadores do direito quanto ao deferimento do aproveitamento de créditos desse imposto.

Isso porque, além da amplitude do direito ao aproveitamento de créditos nos termos do Texto Constitucional, nos termos antes expostos, o conteúdo mínimo do princípio da não cumulatividade do ICMS autoriza a compensação do imposto referente aos insumos das atividades-fim.

De modo geral, entende-se por insumo os gastos e investimentos relativos aos produtos, serviços e outros que sejam necessários e fundamentais à concreção das atividades das empresas, contribuindo para a formação do produto ou serviço final. 
Os insumos podem ser considerados espécie do gênero "bens intermediários", pois aqueles são essenciais para a formação do produto ou serviço final, enquanto esses também contribuem para o resultado, porém indiretamente.

Tem-se, assim, a estrita relação entre a definição de insumos e o critério da essencialidade, isso porque é necessário analisar a atividade-fim da pessoa jurídica para identificar quais são os elementos que entram no processo de produção e prestação de serviços.

Todos os bens adquiridos e serviços utilizados pelos prestadores de serviços e que sejam essenciais à concreção de suas atividades-fim devem gerar o direito ao aproveitamento de créditos de ICMS, por força do critério mínimo do princípio da não cumulatividade.

Inclusive, o sistema jurídico permite a apropriação de créditos atinentes à aquisição de bens destinados ao ativo permanente e ao uso e consumo (embora haja previsão de diferimento), o que revela a imprescindibilidade dessas aquisições para a concreção das atividades das pessoas jurídicas.

Evidente, portanto, que os serviços de transporte e comunicação tributados pelo ICMS têm particularidades que exigem a correta análise da natureza de suas atividades.

Deve-se privilegiar o critério da essencialidade, a fim de identificar quais são os bens e serviços que dão direito à apropriação de créditos de ICMS, por força do princípio da não cumulatividade. Entender de modo diverso é subverter as características elementares da operacionalização e, por conseguinte, permitir a violação de princípios-valores, o que não é aceito pela atual ordem constitucional. 


\section{REFERÊNCIAS}

ALCHOURRÓN, Carlos Eduardo; BULYGIN, Eugenio. Sobre la existencia de las normas jurídicas. México: Distribuiciones Fontamara, 1997.

ATALIBA, Geraldo. Hipótese de Incidência Tributária. São Paulo: Revista dos Tribunais, 1973.

. ICMS na Constituição. Revista de Direito Tributário, São Paulo: Revista dos Tribunais, São Paulo, v. 15, n. 57, p. 90-114, jul./set. 1991.

BARRETO, Aires Fernandino. Curso de Direito Tributário Municipal. 2. ed. São Paulo: Saraiva, 2012.

Imposto sobre Serviços de Qualquer Natureza. Revista Dialética de Direito Tributário, São Paulo: Dialética, v. 29, n. 90, p. 184-196, 1984.

BARRETO, Paulo Ayres. Imposto sobre a Renda e Preços de Transferência. São Paulo: Dialética, 2001.

. Planejamento Tributário Limites Normativos. São Paulo: Noeses, 2016.

BECHO, Renato Lopes. Tributação das Cooperativas. 3. ed. São Paulo: Dialética, 2005.

BORGES, José Souto Maior. Crédito do IPI Relativo a Insumo Isento. Revista Dialética de Direito Tributário, São Paulo: Dialética, n. 48, p. 159-171, set. 1999.

BOWMAN, Alan; AVERIL, Cameron; GARNSEY, Peter. The Cambridge Ancient History. The Crisis of Empire, A.D. 193-337. 2. ed, v. XII. Cambridge: Cambridge University Press, 2005.

BROKELIND, Cécile (Ed.). Principles of Law: Function, Status and Impact in EU Tax Law. Amsterdam: IBFD, Nov. 2014.

CARRAZZA, Roque Antonio. ICMS. 17. ed. São Paulo: Malheiros, 2015.

O ICMS na Constituição. 17. ed. São Paulo: Malheiros, 2015.

CARVALHO, Aurora Tomazini de (Org.). Constructivismo Lógico-Semântico. V. 1. São Paulo: Noeses, 2014.

. Curso de Teoria Geral do Direito - O Constructivismo Lógico-Semântico.

5. ed. São Paulo: Noeses, 2016. 
- O Construtivismo Lógico-Semântico como Método de Trabalho na Elaboração Jurídica. In: São Paulo: Noeses, 2014. p. 13-39.

CARVALHO, Paulo de Barros. Algo sobre o Construtivismo Lógico-Semântico. In: CARVALHO, Aurora Tomazini de (Org.). Constructivismo Lógico-Semântico. V. 1. São Paulo, 2014. p. 3-11.

2013.

Aspectos Polêmicos de PIS e Cofins. São Paulo: Lex Magister; CEU, . Curso de Direito Tributário. 27 ed. São Paulo: Saraiva, 2016.

. Guerra Fiscal - Reflexões sobre a concessão de benefícios no âmbito do ICMS. 2. ed. São Paulo: Noeses, 2014.

Não-Incidência do ICMS na Atividade dos Provedores de Acesso à Internet. Revista Dialética de Direito Tributário, n. 73, p. 97-104, 2001.

Não-incidência do ICMS na atividade dos provedores de acesso à internet. In: TORRES, Heleno Taveira (Coord.). Direito Tributário das Telecomunicações. São Paulo: IOB Thomson, 2004. p. 487-496.

COÊLHO, Sacha Calmon Navarro. Curso de Direito Tributário Brasileiro. 9. ed. Rio de Janeiro: Forense, 2007.

; DERZI, Misabel Abreu Machado. ICMS - Direito ao Creditamento Princípio da Não-Cumulatividade. Revista Dialética de Direito Tributário, São Paulo: Dialética, n. 102, p. 141-156, mar. 2004.

CORAZZA, Edison Aurélio. ICMS sobre Prestações de Serviços de Comunicação. São Paulo: Quartier Latin, 2006.

COSTA, Alcides Jorge. ICM: Fatos Geradores do ICMS e do Imposto Sobre Comunicação. In: HARADA, Kiyoshi; COSTA, Alcides Jorge (Coords.). Temas de Direito Tributário. São Paulo: Juarez de Oliveira, 2000. p. 1-7.

DE PLÁCIDO E SILVA, Oscar Joseph. Vocabulário Jurídico. 31. ed. Atualizadores: Nagib Slaibi Filho e Priscila Pereira Vasques Gomes. Rio de Janeiro: Forense, 2014.

DERZI, Misabel Abreu Machado. Atualização. BALEEIRO, Aliomar. Direito Tributário Brasileiro. 11. ed. Rio de Janeiro: Forense, 2001. $\overline{\text { Rey, } 1997 .}$

Direito Tributário Aplicado - Estudos e Pareceres. Belo Horizonte: Del 
. Distorções do princípio da não-cumulatividade no ICMS - Comparação com o IVA europeu. In: COÊLHO, Sacha Calmon Navarro. Temas de Direito Tributário I. Belo Horizonte: Livraria Del Rey, 1998. p. 9-151.

DINIZ, Maria Helena. Dicionário Jurídico. V. 2. São Paulo: Saraiva, 1998.

ESTRELLA, André Luiz Carvalho. O Crédito Financeiro do ICMS - Artigo 20, §1ㄹ, da Lei Complementar o 87/96 - Bens de Uso, Consumo e Ativo Permanente e o seu Regime no IVA do Mercado Europeu. Revista de Direito Processual Geral, Rio de Janeiro, n. 57, p. 64-93, 2003.

EUROPE. European Union law. Case C-520/10. Judgment of the Court (Third Chamber). 3 May 2012.

FERREIRA, Aurélio Buarque de Holanda. Novo Dicionário Aurélio da Língua Portuguesa. Rio de Janeiro: Nova Fronteira, 1999.

GALVÃO, Flávio. ICMS sobre Transportes. São Paulo: Quartier Latin, 2010. BARRETO, Aires Fernandino. Base de cálculo, Alíquota e Princípios Constitucionais. São Paulo: Revista dos Tribunais, 1987.

GRECO, Marco Aurélio. Conceito de Insumo à Luz da Legislação de PIS e COFINS. Revista Fórum de Direito Tributário, Belo Horizonte, v. 6, n. 34, p. 9-30, jul./ago. 2009.

. Não-Cumulatividade no PIS e na COFINS. Revista Fórum de Direito Tributário (RFDT), Belo Horizonte, ano 2, n. 12, p. 29-51, nov./dez. 2004.

. Transações Eletrônicas - Aspectos Jurídicos. In: . Internet $e$ Direito. 2. ed. São Paulo: Dialética, 2000. p. 11-43.

HOUAISS, Antônio. Dicionário Houaiss da Língua Portuguesa. Rio de Janeiro: Objetiva, 2001.

JAMES, Kathryn. The Rise of the Value-Added tax. Cambridge: Cambridge University Press, 2015 (Cambridge Tax Law Series).

LANG, Joachim. Justiça Fiscal e Globalização. Tradução de Victor Borges Polizelli. Revista de Direito Tributário Atual, São Paulo: Dialética, n. 24, p. 71-90, 2010.

MACHADO, Hugo de Brito. A Não-Cumulatividade do ICMS como Princípio Constitucional. Revista Dialética de Direito Tributário, São Paulo: Dialética, n. 242, p. 55-58, nov. 2015. 
Do Conceito de Insumo no Contexto da não Cumulatividade dos Tributos. Revista Dialética de Direito Tributário, n. 227, p. 66-72, ago. 2014.

MANEIRA, Eduardo; MAIA, Marcos Correia Piqueira. A efetivação do princípio da não-cumulatividade para os prestadores de serviços tributados pelo ICMS. In: GOMES, Marcus Lívio; VELLOSO, Andrei Pitten (Orgs.). Sistema Constitucional Tributário - Dos fundamentos teóricos aos hard cases tributários - Estudos em Homenagem ao Ministro Luiz Fux. Porto Alegre: Livraria do Advogado, 2014. p. 131-144.

; MAIA, Marcos Correia Piqueira. Tributação e Telecomunicações. In: RABELO FILHO, Antonio Reinaldo; ALVES, Gustavo Baptista; SILVA FILHO, Paulo Cesar da; MENDONÇA, Victor Furtado de (Coords.). ABETEL. São Paulo: Quartier Latin, 2016. p. 161-181.

MARTINS, Ives Gandra da Silva. Direito à Compensação do ICMS incidente sobre Combustíveis e Insumos nas Operações de Transporte mesmo quanto Realizadas mediante Subcontratação. Revista Dialética de Direito Tributário, São Paulo: Dialética, n. 151, p. 131-143, abr. 2008.

O Princípio da Não-Cumulatividade do ICMS - Crédito, pelas Empresas de Transporte, do Imposto Pago nos Insumos das Subcontratadas. Revista Dialética de Direito Tributário, São Paulo: Dialética: n. 25, p. 137-146, out. 1997.

MELO, José Eduardo Soares de. Não-Cumulatividade Tributária. São Paulo; Fortaleza: Dialética, 2009.

; LIPPO, Luiz Francisco. A Não-Cumulatividade Tributária (ICMS, IPI, ISS, PIS e COFINS). 3. ed. São Paulo: Dialética, 2008.

MENDONÇA, Christiane. A Não-Cumulatividade do ICMS. São Paulo: Quartier Latin, 2005.

MORCHÓN, Gregorio Robles. Teoria del Derecho (Fundamentos de La Teoria Comunicacional del Derecho). v. 1. Madrid: Civitas, 1998.

MOREIRA, André Mendes. A Não-Cumulatividade dos Tributos. 2. ed. São Paulo: Noeses, 2012.

MOSQUERA, Roberto Quiroga. Direito Monetário e Tributação da Moeda. São Paulo: Dialética, 2006.

ORGANISATION FOR ECONOMIC CO-OPERATION AND DEVELOPMENT (OECD). Consumption Tax Trends 2014. VAT/GST and Excise Rates, Trends and Policy Issues. Paris: OECD, Dec. 10, 2014.

REALE, Miguel. Introdução à Filosofia. São Paulo: Saraiva, 1994. 
SCHOUERI, Luís Eduardo. Direito Tributário. 3. ed. São Paulo: Saraiva, 2013.

SILVA, Eric Castro e. Definição de "Insumos" para Fins de PIS e Cofins Não Cumulativos. Revista Dialética de Direito Tributário, São Paulo: Dialética, n. 170, p. 23-30, dez. 2009.

TOMÉ, Fabiana Del Padre. A Prova no Direito Tributário. 4. ed. São Paulo: Noeses, 2016.

Definição do Conceito de "Insumo" para a não-cumulatividade do PIS e COFINS. São Paulo: 14 jun. 2013, p. 9. Disponível em: <www.ibet.com.br/definicao>. Acesso em: 17 nov. 2016.

TORRES, Heleno Taveira. O IVA na Experiência Estrangeira e a Tributação das Exportações no Direito Brasileiro. Revista Fórum de Direito Tributário (RFDT), Belo Horizonte, ano 3, n. 16, p. 43-62, jul./ago. 2005.

VILANOVA, Lourival. As Estruturas Lógicas e o Sistema do Direito Positivo. 4. ed. São Paulo: Noeses, 2010.

XAVIER, Helena de Araújo Lopes. O conceito de comunicação e telecomunicação na hipótese de incidência do ICMS. Revista Dialética de Direito Tributário, São Paulo: Dialética, n. 72, p. 72-87, 2001. 